\title{
Combined Effects of Perceived Politics and Psychological Capital on Job Satisfaction, Turnover Intentions, and Performance
}

\author{
Muhammad Abbas \\ Faculty of Management Sciences \\ Riphah International University, Sector I-14, Hajj Complex, Islamabad \\ PAKISTAN \\ Email: muhammad.abbas@riu.edu.pk \\ Usman Raja* \\ Faculty of Business \\ Brock University \\ 500 Glenridge Ave. St. Catharines, ON L2S 3A1, CANADA \\ Email: usmanraja@gmail.com; uraja@brocku.ca
}

Wendy A. Darr

Defense Scientist

Directorate of Military Personnel Research and Analysis

National Defense Headquarters

Ottawa, ON, Canada K1A 0K2

Email:WENDY.DARR@forces.gc.ca

\author{
Dave Bouckenooghe \\ Faculty of Business \\ Brock University, \\ 500 Glenridge Ave. St. Catharines, ON L2S 3A1 \\ CANADA \\ Email: dbouckenooghe@brocku.ca
}

\section{* Corresponding author}

Acknowledgements: This research was partially supported by Brock University research grant 112-348066. The authors would like to thank Gary Johns, Gary Greguras (Action Editor), and two anonymous reviewers for their valuable suggestions that helped us in improving this paper. We also thank Aliya Moeen Zafar for her help in proofreading and editing this paper.

Citation: Abbas, M. Raja, U., Darr, W., \& Bouckenooghe, D. (August 2012). Combined Effects of Perceived Politics and Psychological Capital on Job Satisfaction, Turnover Intentions, and Performance.

Journal of Management DOI: 10.1177/0149206312455243.

This is final accepted version of the article (without proofread). The final publication is available at http://jom.sagepub.com/content/early/2012/08/08/0149206312455243.abstract 


\begin{abstract}
With a diverse sample $(n=231$ paired responses $)$ of employees from various organizations in Pakistan, we tested for the main effects of perceived organizational politics and psychological capital on turnover intentions, job satisfaction, and supervisor rated job performance. We also examined the moderating influence of psychological capital in the politics - outcomes relationships. Results provided good support for the proposed hypotheses. While perceived organizational politics was associated with all outcomes, psychological capital had a significant relationship with job satisfaction and supervisor rated performance only. As hypothesized, the negative relationship of perceived organizational politics with job satisfaction and supervisor rated performance was weaker when psychological capital was high. However, the result for turnover intentions was counter to expectations where politics - turnover intention relationship was stronger when psychological capital was high.
\end{abstract}

Keywords: Perceived Politics; Psychological Capital; Job Performance; Job Satisfaction; Turnover Intentions 


\section{COMBINED EFFECTS OF PERCEIVED POLITICS AND PSYCHOLOGICAL CAPITAL ON JOB SATISFACTION, TURNOVER INTENTIONS, AND PERFORMANCE}

Over the past couple of decades, perceived organizational politics (POP) has remained an important subject of inquiry in the field of organizational behavior and is commonly viewed as a source of detrimental consequences for organizational members (e.g., Chang, Rosen, \& Levy, 2009; Ferris, Russ, \& Fandt, 1989). However, despite two recent meta-analytic studies, the effects of POP on outcomes are still inconclusive. For example, Miller, Rutherford, and Kolodinsky's (2008) meta-analysis examining perceived politics and various employee outcomes such as job stress, job satisfaction, turnover, and organizational commitment suggests that POP is generally detrimental to personal and organizational effectiveness; yet their findings also reveal variation in effects across outcomes and certain settings. Specifically, the effects for job performance were much smaller than for other outcomes, and public sector employees were more likely to leave the organization in the face of organizational politics compared to private sector employees. In addition, the effects for organizational commitment were much lower in international samples than in domestic samples, suggesting the need for further exploration of POP theory in different cultures to determine its boundary conditions.

Pointing to the lack of a theoretical understanding of how perceptions of politics influence employee outcomes, Chang et al. (2009) called for future researchers to examine the contextual and individual difference factors as moderators in such relationships. Although few studies have attempted to explore the moderating role of individual difference variables in the relationship between perceived politics and various outcomes, there remains a lack of understanding of the influence of an individual's composite psychological resources, particularly 
hope and self-efficacy, on the relationship between perceived politics and outcomes such as turnover intentions, job satisfaction, and job performance.

For example, Kacmar, Collins, Harris, and Judge (2009) found that Core Self Evaluations (which includes generalized self-efficacy) exacerbated the relationship between POP and job performance. Bozeman, Perrewe, Hochwarter, and Brymer (2001) found some mixed evidence whereby self-efficacy intensified the negative effects of perceived politics on job satisfaction; however, it did not moderate between POP-turnover intentions and POP-job stress relationships. On the contrary, we draw upon Conservation of Resource Theory (Hobfoll, 2011) to argue that psychological capital (PsyCap) comprising hope and self-efficacy will act as 'a solid resource reservoir' (Hobfoll, 2002: 318) and reduce the negative effects of politics on work outcomes. Thus, the study of psychological capital as a holistic core construct would better explain the moderating role of such constructs in the POP - outcomes relationships and would advance further knowledge in this domain.

In addition, it is important to note that the majority of studies in this domain of research have been conducted in developed countries of North America and Europe. Tsui, Nifadkar, and Ou (2007) suggested that unless we test the theories largely developed in the US in non-Western settings, researchers and practitioners would have little confidence about their generalizability in other regions. We believe that our study will address this gap as it provides a rare opportunity to examine the applicability and validity of concepts largely developed in Western cultures.

\section{THEORY AND HYPOTHESES}

\section{POP, PsyCap, and Workplace Outcomes}

Politics is an inevitable component of an organization's social fabric, which different people may perceive differently. Despite some discussion that some individuals thrive on 
politics, using it to their advantage through the development of political skill (Ferris, Perrewe, Anthony, \& Gilmore, 2000), this treatment of POP has typically been made in reference to the upper organizational echelon of executives (see Perrewe, Ferris, Frink, \& Anthony, 2000). In the current study, we define perceived organizational politics as an individual's perceptions of others' self-interested acts or behaviors, frequently associated with manipulation of organizational policies, often using coercive tactics even at the expense of others for short-term gains (Kacmar \& Ferris, 1991). These behaviors are perceived as subversive and contradict with the interests of other individuals and the organization (Vigoda, 2000).

As an antecedent to workplace outcomes, POP has generally been regarded as a stressor. For example, while examining stressors, Cavanaugh, Boswell, Roehling, and Boudreau (2000) found that POP loaded on a factor called hindrance stressors. The 'organizational development literature' also conceives perceived politics as a stressor that has detrimental impact on a person's resources. More specifically, Crawford, Lepine, and Rich (2010) suggest that POP activates an energy depletion process whereby an employee's sustained increases in effort to meet the perceived demands is met with an increase in compensatory actions and psychological processes that drain a person's individual resources. In addition, Chang et al. (2009) metaanalytically examined perceptions of politics as a hindrance stressor to find a stress-related connection to performance. In the light of these findings, POP is regarded as a hindrance stressor in the present examination.

Despite recent meta-analytic evidence for variation in the effects of POP on outcomes (e.g., Miller et al., 2008), perceived politics can be summarized as having a generally positive relationship with turnover intentions (Chang et al., 2009), and a negative relationship with job satisfaction (Chang et al., 2009; Ferris \& Kacmar, 1992) and job performance (Vigoda, 2000). 
There is also some evidence available for the harmful effects of perceived organizational politics across cultures. For example, Vigoda (2001) found that British and Israeli employees reported similar levels of organizational politics at the workplace, however British employees responded to perceived politics with higher turnover intentions than Israeli employees. Vigoda (2001) attributed these findings to the difference in power distance (PD) between both cultures.

Britain ranks higher on the national cultural dimension of power distance as compared to Israel (Hofstede, 1983). In high power distance cultures, individuals usually accept a hierarchical order in which everybody has a place. In these cultures, interpersonal conflict is considered a disruption of ordinary life (Hofstede, 1991). Similar to Britain, Pakistan also ranks high on power distance (Hofstede, 1983). In addition, Pakistan scores high uncertainty avoidance (UA), reacting adversely to uncertainty or a lack of control. Hofstede (2001) suggests that the combination of these two dimensions results in situations where leaders have ultimate power and authority, and that rules, laws, and regulations are developed to reinforce such leadership. In such a context, formal rules and regulations exist to further managerial interests at the expense of subordinates (Kacmar \& Ferris, 1991), prompting turnover and lowered job satisfaction as employees' reactions to perceived politics in the workplace. Hence, we expect to replicate the findings that perceived politics would have harmful effects on outcomes in Pakistan.

Hypothesis 1: Perceived organizational politics will be positively related to turnover intentions and negatively related to job satisfaction and job performance.

Lately, researchers in domains of positive organizational behavior have stressed the need to focus on positive strengths and well-being of individuals in the workplace (Luthans \& Youssef, 2007). The positive psychological approaches have emerged with a focus on what is right with people, rather than the traditional approaches of what is wrong with people (Luthans, 
2002). This line of thinking has resulted in the coining of a term known as psychological capital (Avey, Luthans, \& Youssef, 2010).

Although psychological capital (PsyCap) comprises of four components named hope, optimism, self-efficacy, and resilience (Luthans, Youssef, \& Avolio, 2007), research considers hope and efficacy to be the most significant in predicting various work-related outcomes (e.g., Luthans, Avolio, Avey, \& Norman, 2007; Stajkovic \& Luthans, 1998a; Youssef \& Luthans, 2007). Efficacy is “the employee's conviction or confidence about his or her abilities to mobilize the motivation, cognitive resources, or courses of action needed to successfully execute a specific task within a given context" (Stajkovic \& Luthans, 1998b: 66). Similarly, hope is "a positive motivational state that is based on an interactively derived sense of successful (a) agency (goal-directed energy) and (b) pathways (planning to meet goals)" (Snyder, Irving, \& Anderson, 1991: 287).

Conceptually, self-efficacy and hope are assumed to be more significant factors than optimism and resiliency in predicting attitudes and organizational behavior (Bandura, 2012). Self-efficacy is considered to best meet the inclusion criteria for PsyCap in positive organizational behavior (Luthans, 2002). Similarly, of the three remaining facets of PsyCap 'hope' is the strongest predictor of work related outcomes and shares the strongest underlying common denominator with self-efficacy and (Luthans, 2002; Magaletta \& Oliver, 1999; Youssef \& Luthans, 2007). Efficacy and hope share the components of internalized motivation and energy, or the positive expectation of success for the reason of belief in one's individual abilities. Highly efficacious and hopeful employees would set challenging goals for themselves and selfselect into challenging assignments with motivation and tenacious effort toward success. Therefore, we focus on the efficacy and hope dimensions of psychological capital in this study. 
Previous research has found PsyCap to be positively associated to job performance and satisfaction (Luthans, Avolio, et al., 2007), and negatively associated to organizational cynicism and turnover intentions (Avey et al., 2010). Based on its definition, individuals with high PsyCap are believed to possess the cognitive capacity of self-regulation (Bandura, 1997) that offers initiative, energy, and self-discipline necessary to reach one's goals (Luthans \& Youssef, 2007). Thus we believe that being personal and psychological in nature, psychological capital will have similar effects on outcomes as those observed in US settings. Psychological capital, especially hope and self-efficacy, will give individuals more confidence and stimulate positive thinking, which would result in better performance, higher satisfaction, and lower possibility of leaving the job. Therefore, we suggest that:

Hypothesis 2: PsyCap will be negatively related to turnover intentions and positively related to job satisfaction and job performance.

\section{The Moderating Role of Psychological Capital}

Recent studies have shown the relevance of COR theory to serve as a conceptual foundation for the role of individuals' psychological resources to cope with harmful effects of organizational politics (Kapoutsis, Papalexandris, Nikolopoulos, Hochwarter, \& Ferris, 2011). Hindrance stressors tend to dampen motivation, which thwarts performance and personal goal attainment and growth (LePine, Podsakoff, \& LePine, 2005). This theory helps in delineating the processes by which resources such as psychological capital assist individuals to cope with stressors. Individuals who possess key resources such as hope and self-efficacy 'might be more capable of selecting, altering, and implementing their other resources to meet stressful demands' (Hobfoll, 2002: 308).

When faced with an environmental stressor (e.g., organizational politics), individuals 
exert efforts to successfully cope with it in order to maintain a balance (Hobfoll, 2011). The success of these efforts depends on the psychological resources these individuals possess (Treadway et al., 2005). Therefore, individual differences in internal psychological resources are likely to play an influential role in the attribution of resource loss as salient. Here, resource loss could refer to perceived loss of tangible goals due to politics in the workplace or to a perceived loss of cognitive or emotional coping resources dedicated to addressing politics as a stressor.

We argue that high PsyCap individuals, because of their level of confidence in pursuing challenging tasks (Bandura, 1997), their capacity to derive multiple pathways to be successful (Snyder, 1994), and their ability to persevere in the face of obstacles (Stajkovic \& Luthans, 1998a), are less likely to perceive organizational politics as threatening or harmful. These individuals possess the cognitive capacity of self-regulation (Bandura, 1997) that offers initiative, pro-activeness, and self-discipline necessary to reach the desired goals, even when there is a lack of extrinsic motivators (Luthans \& Youssef, 2007) and absence of feedback (Judge, Jackson, Shaw, Scott, \& Rich, 2007). Therefore, they are less likely to experience the typical negative outcomes (e.g., lowered job satisfaction and performance) associated with organizational politics.

Seligman and Csikszentmihalyi (2000) posit that hope plays the role of a buffering agent against psychological distress, addiction, and dysfunctional behavior. Studies have demonstrated a strong relationship between hope and academic and athletic performance, mental and physical health, and the ability to cope with adversity (Snyder, 1994; Snyder et al., 1991). Similarly, Caprara, Barbaranelli, Pastorelli, and Cervone (2004) investigated the ability of efficacy beliefs to predict psychosocial outcomes among high school students. These authors found that selfefficacy beliefs predicted lower problem-behaviors (depression and aggression) and attainment 
of greater grades. Moreover, high efficacious individuals are less likely to expect failures or loss of confidence when faced with negative feedback, setbacks, uncertainties, and difficulties (Bandura \& Locke, 2003).

When combined, these psychological resource capacities form the cognitive, emotional, and motivational bases (Bandura \& Locke, 2003; Seligman \& Csikszentmihalyi, 2000) through which individuals mitigate the detrimental effects of negativity (Youssef \& Luthans, 2007). Based on these arguments, we believe that when individuals perceive the organizational activities and procedures to be politically driven, their psychological capital may help them to minimize the salience of resource loss associated with these activities, allowing them to cope better with these stressors, thereby reducing the influence of POP on outcomes. Consequently, we suggest:

Hypothesis 3: PsyCap will moderate the relationship between POP and outcomes (turnover intentions, job satisfaction, and job performance) such that the relationship will be weaker when PsyCap is high.

\section{METHODS}

\section{Sample and Data Collection Procedures}

Perceptions of politics can vary considerably across organizations. In order to capture maximum variance in politics, we decided to collect data from a variety of organizations. Through personal and professional contacts of the first author, we were able to gain access to employees in six branches of private banks, local offices of two textile-manufacturing firms, three offices of a government ministry, and customer service offices of a telecommunication company in Faisalabad, which is the third largest city of Pakistan. We decided to target all whitecollar employees in each location for two reasons. First, we believe that organizational politics is 
more likely to play a role among managers and professional workers because they have to manage people and resources. Second, due to low education levels, we believed that lower level blue collar workers would not be able to respond to a questionnaire in English effectively.

We collected data through onsite administration of a questionnaire with self and supervisory-report versions. A cover letter explained the purpose of the study to the respondents, assured them of strictest confidentiality of responses, and mentioned that participation was voluntary. Respondents completed the self-report version that contained items related to POP, PsyCap, turnover intentions, and job satisfaction. In addition, they reported their name, age, gender, occupational level, education, and work experience in the demographics part of the survey. The supervisor of each respondent completed the supervisor-report version that contained questions on job performance. Both the respondents and their supervisors returned the completed questionnaires to one of the authors without having access to each other's responses. Each supervisor knew his / her subordinates for more than six months and had done at least one performance appraisal for him / her.

Of the 300 distributed questionnaires, we received 237 completed self-report responses. We were able to get supervisor reports from 79 supervisors for 231 of the respondents. Therefore, our final response rate for the 231 usable paired (231 employee and 231 supervisor responses) responses was $77 \%$. We distributed 48 surveys among the government workers, 154 in bank branches, 33 in the telecom company, and 65 in the textile firms. The response rates for government offices, banks, telecom, and textile firms were $75 \%, 78 \%, 76 \%$, and $75 \%$ respectively. The majority of respondents $(80.1 \%)$ were male with an average age of 31 years $(S D=8.1)$. The sample included several occupational levels comprising $16 \%$ entry level (clerical and IT staff) workers, $80 \%$ supervisory and middle managers, and $4 \%$ upper middle and top- 
level managers. The average tenure was $4.80(S D=6.48)$ years. About $31 \%$ of the respondents had an undergraduate university degree while $69 \%$ held graduate degrees.

A total of 79 supervisors reported for the 231 respondents, which could result in nesting of data. With supervisor as a grouping variable, we ran the null model in HLM to calculate between and within group variance for job performance in our dataset. This procedure estimated whether it was feasible to run a more complex model controlling for nesting of data based on supervisor as the higher-order level in our dataset. The results revealed that within group variance $\left(R^{2}=.27\right)$ was substantially higher than between group variance $\left(R^{2}=.08\right)$ and the $\mathrm{F}$ statistic for the ratio of the two variances was not significant $(F(78,152)=.22$, n.s $)$. Put differently, the data suggest that supervisors as a grouping variable do not explain sufficient variance to justify the use of HLM analysis controlling for nesting of data (Bryk \& Raudenbush, 1992).

\section{Measures}

All constructs were measured using self-reported instruments except for job performance, which was measured using supervisory ratings to avoid method bias issues. Responses for all variables, with exception of PsyCap, were assessed using a 5-point Likert type scale with anchors of 1 = 'strongly disagree', 2 = 'disagree', 3 = 'neither disagree/nor agree', 4 = 'agree', and $5=$ 'strongly agree'. The responses for psychological capital were measured using a 6-point Likert-scale with anchors ranging from 1 = 'strongly disagree', 2 = 'disagree', 3 = 'somewhat disagree' $4=$ 'somewhat agree', 5 = 'agree', to 6 = 'strongly agree'. For all measures, higher score corresponded to higher levels of the construct.

Perceptions of Organizational Politics (POP). We used the 12-item Perceptions of Organizational Politics Scale (POPS) by Kacmar and Ferris (1991) to assess this construct. This 
scale contains three sub-dimensions of perceived politics: general political behavior (six items), go along to get ahead (four items), and pay and promotion policies (two items). Examples of items include "people build themselves up by tearing others down", for the first dimension, "employees are encouraged to speak out (reverse-coded)" for the second, and "Pay and promotion policies are not politically applied (reverse-coded)" for the third dimension.

As we were interested in examining the effects of overall perceived politics on outcomes, we conducted a second order confirmatory factor analysis to see if the three-dimensional construct did load on to a single latent factor. The results of CFA revealed a good fit for a latent single factor model $\left(\chi^{2}=84.76, d f=53, C F I=.94, G F I=.94, I F I=.95\right.$, RMSEA $\left.=.05\right)$. Therefore, we used an additive measure by taking average of all items to create overall POP such that high scores reflected high perceived politics ${ }^{1}$. This treatment of POP measure has been used in past research (e.g., Randall, Cropanzano, Bormann, \& Birjulin, 1999; Rosen, Levy, \& Hall, 2006). Cronbach's alpha reliability of the POP measure was .73.

Psychological Capital (PsyCap). We measured efficacy and hope using 12-items (six items for each measure) from Psychological Capital Questionnaire (Luthans, Youssef, et al., 2007). Examples of items include "if I should find myself in a jam at work, I could think of many ways to get out of it" for hope; "I feel confident analyzing a long-term problem to find its solution" for efficacy. We conducted a second order CFA to see if both hope and efficacy loaded on to a single latent factor. Results yielded a good fit for a latent single factor model $\left(\chi^{2}=\right.$ $102.91, d f=52, C F I=.95, G F I=.94, I F I=.95, R M S E A=.06)$. Therefore, to create overall psychological capital, we averaged scores on all 12 items such that a high score reflected high psychological capital. The internal consistency reliability of PsyCap was .89.

\footnotetext{
${ }^{1}$ We ran our analyses using a measure based on mean of the means of dimensions. The results did not differ compared to the additive measure.
} 
Outcomes. A 3-item scale by Vigoda (2000) was used to measure turnover intentions. This measure included items such as "I often think about quitting this job". The reliability of this measure was .76. We measured overall job satisfaction using a 6-item scale developed by Agho, Price, and Mueller (1992), which contained questions such as "I feel fairly well satisfied with my present job" and "I find real enjoyment in my work." The reliability of this measure was .67. Supervisor responses to a 7-item scale developed by Williams and Anderson (1991) were used to measure job performance. Sample items include, "This person adequately completes assigned duties" and "This person performs tasks that are expected of him/her." The alpha reliability was .77.

Control Variables. We used age and tenure as control variables because of their possible effects on job outcomes. A one-way ANOVA comparing job satisfaction, job performance, and turnover intentions across gender, education, and organizations revealed that there were significant differences in turnover intentions $(F=34.02, p<.000)$ and job satisfaction $(F=$ $14.60, p<.000)$ across organizations. Post-hoc analyses showed that the differences were only between the two groups of organizations in the public and private sectors. Hence, we used a dummy variable $(0=$ "Private," $1=$ "Public") to control for the effects of organization type.

\section{RESULTS}

\section{POP, PsyCap, and Outcomes}

Table 1 shows the descriptive statistics, bivariate correlations, and estimates of reliability (coefficient alpha) for all measures. All the zero-order bivariate correlations were in the expected direction.

Insert Table 1 about here 
We used multiple linear regression analyses to test all main effect hypotheses (H1 and H2). We entered age, tenure, and organizational type in the first step followed by the independent variables. Table 2 (step 3) presents the results for the main effects of POP and PsyCap on the outcomes. POP was positively related to turnover intention $(\beta=.26, p<.001)$ and negatively to job satisfaction $(\beta=-.29, p<.001)$ and job performance $(\beta=-.21, p<.05)$. These results support hypothesis 1 . Similarly, Table 2 shows that psychological capital was positively related to job satisfaction $(\beta=.56, p<.001)$ and job performance $(\beta=.54, p<.001)$, but its relationship with turnover intentions $(\beta=-.01, n . s)$ was not significant. These results render support to hypothesis 2 for satisfaction and performance only.

Insert Table 2 about here

\section{Moderating Influence of PsyCap}

We used moderated multiple regression (MMR) analyses (Cohen, Cohen, West, \& Aiken, 2003) to test hypotheses 3 . We entered the control variables in the first step followed by independent and the moderator variables in the next step. In the third step, we entered a product term of independent and moderator variable, which if significant, confirmed moderation. We centered the variables by subtracting the overall mean from the individual values for the moderated regression analyses. In addition, we also obtained the variance inflation factor (VIF) scores (Hair, Anderson, Tatham, \& Black, 1998) and the tolerance statistics (Tabachnick \& 
Fidell, 2001), which measure the extent to which collinearity among predictors affects the precision of a regression model. VIF scores of less than 5 (Chatterjee \& Price, 1991) and tolerance scores above .10 (Hair et al., 1998) are typically considered acceptable. The VIF scores were below 3 (Tolerance $>.3$ ) in all analyses indicating that multicollinearity was not a problem.

Results presented in Table 2 (step 3) show that controlling for the effects of POP and PsyCap, the interaction term of POP x PsyCap was significant for turnover intentions $(\beta=.14, p$ $\left.<.05 ; \Delta R^{2}=.02, p<.05\right)$, job performance $\left(\beta=.33, p<.001 ; \Delta R^{2}=.09, p<.001\right)$, and job satisfaction $\left(\beta=.17, p<.01 ; \Delta R^{2}=.02, p<.01\right)$. The additional variance explained by the interaction term falls within or exceeds the typical range for moderator effects in nonexperimental field studies (e.g., Chaplin, 1991).

We plotted the significant interactions for high and low (Mean $\pm S D$ ) values of the moderator. The plots of the significant interactions are displayed in figures 1 through 3 . Figure 1 shows that, contrary to our hypothesis, the positive POP-turnover intentions relationship was stronger when PsyCap was high. Simple slope tests using the procedure recommended by Aiken and West (1991) revealed that the slope for high levels of PsyCap was significant $(\beta=0.79, p<$ $.001)$, however the slope for low levels of PsyCap was not significant $(\beta=-.23, n s)$. Figure 2 shows the plot of significant interaction for job satisfaction. The slope for high psychological capital was not significant $(\beta=-.04, n s)$, but the slope line for low psychological capital was significant $(\beta=-.74, p<.01)$. Figure 3 shows the plot of simple slopes for job performance. The relationship between perceived politics and job performance was significantly negative for low levels of PsyCap $(\beta=-1.26, p<.001)$ and significantly positive for high levels of PsyCap $(\beta=$ $.32, p<.01)$. Hence, the results supported hypothesis 3 for job performance and job satisfaction only. 
Insert Figures 1 through 3 about here

Figures 2 and 3 indicate that there was one outlier cell, where psychological capital was low and perceived organizational politics was high, tended to have greater effects. Therefore, we conducted the Bobko procedure (Bobko, 1986) as a robustness check for ordinal interaction effects. The results for the first contrast (comparing means for low politics and high PsyCap; low politics and low PsyCap; high politics and high PsyCap) using a one-way analysis of variance showed that there were no significant differences between the three means $\left(F_{\text {performance }}=1.59\right.$, n.s.; $\left.F_{\text {satisfaction }}=1.64, n . s.\right)$. The second contrast revealed that these three conditions were significantly different from the condition in which respondents were scoring high on politics and low on PsyCap $\left(t_{\text {performance }}=5.19, p<0.001 ; t_{\text {satisfaction }}=4.49, p<0.001\right)$.

\section{DISCUSSION}

Despite general agreement amongst researchers, empirical evidence has revealed variations in the influence of POP on outcomes. In this research, we not only tested for the moderating role of psychological capital in accounting for some of the observed variation in effects, but also incorporated the COR theoretical framework to better understand how psychological capital of hope and efficacy can play a role in employee efforts to address POP as a hindrance stressor.

Our findings clearly support the assertion that when employees perceive politics in the workplace, it reduces their satisfaction and performance and increases the likelihood that they would leave the organization. These findings provide support for the idea of perceived politics 
being detrimental to desired outcomes at workplace. The results of our study also support the idea that psychological capital has a positive effect on desired outcomes such as job satisfaction and job performance, but not intentions to quit. In addition, we found good support for the moderating influence of PsyCap in the POP-outcomes relationship. Interestingly, and contrary to our expectations, the negative relationship between perceived politics and intentions to quit was stronger when PsyCap was high. In retrospect, it is possible that individuals with high psychological capital, being more skillful and confident, think of leaving their jobs if they perceive high politics. They might want to seek better working environment and start looking for options in the wake of high-perceived politics.

For example, it has been suggested that high performers would be more likely to quit when salaries and promotion policies are not aligned (Allen \& Griffeth, 1999), as they have greater tangible resources such as a proven performance track record or other employment opportunities to draw upon (Jackofsky, 1984). Moreover, research on employability suggests that an organizational environment that does not foster its members' development and employability, increases employees' turnover intentions (Nauta, van Vianen, van der Heijden, van Dam, \& Willemsen, 2009). Our findings suggest that psychological resources function the same way, equipping individuals with the cognitive and emotional resources necessary to push them away from a threatening political workplace.

The results for moderating effects of PsyCap in the relationship between POP and job satisfaction and performance were in the expected direction. In both cases, the observed negative relationship was stronger when psychological capital was low. The results indicate that perceived organizational politics is going to be a bigger concern for those with low psychological capital. Perceived politics does not seem to have negative impact on the satisfaction and performance of 
individuals with high psychological resources (i.e., hope and efficacy).

Our finding that psychological capital comprising hope and efficacy acts as a threatneutralizer by reducing the negative effects of politics on performance deserves further attention as it apparently contradicts with the findings of Kacmar et al. (2009). Drawing upon trait activation theory, Kacmar et al. (2009) found that core self-evaluations (which include generalized self-efficacy) intensified the deleterious effects of perceived politics on job performance. We believe that efficacy in conjunction with hope creates a positive resource for individuals that help them to take up the challenge of perceived politics instead of reacting negatively to it. Social psychologists argue that these psychological resources should be studied collectively, as they do not act in isolation (Fredrickson, 2001; Youssef \& Luthans, 2007). Instead, such resources together provide support to each other through a shared underlying mechanism (Luthans, Avolio et al., 2007) that binds them and helps individuals to use them effectively when faced with stressful situations (Hobfoll, 2002). More specifically, a person with no hope and high efficacy is less likely to effectively deal with hurdles as compared to an individual who not only has the required confidence but also has hope that his / her efforts would lead to positive outcomes. We believe that our findings support this line of thought and confirm the idea that efficacy and hope together act to minimize the harmful effects of POP on job outcomes.

A comparison of the zero-order correlations reported in Table 1 against the meta-analytic uncorrected associations reported in Miller et al. (2008) provides an opportunity to compare results for main effects in Western cultures to those examined in this study. With respect to turnover intentions and job performance, it appears that our obtained associations $(r=.30$ for turnover intentions and $r=-.08$ for job performance) are almost identical to those found for 
Miller et al's ( $r=.33$ for turnover intentions and $r=-.09$ for job performance) domestic samples (i.e., North American, generally thought to be low on the cultural values of power distance and uncertainty). Although the perceived politics - satisfaction association was almost half the size $(r$ $=-.21)$ compared to that observed in Miller et al's meta-analysis for domestic samples $(r=-.40)$, the confidence interval (-.73 to -.17) included the correlation observed in our study.

Taken together, these findings suggest that results from the past research in Western context generalize well to Pakistani context. Perceived organizational politics, perhaps, is much more personal in nature and less susceptible to contextual influences. This examination is consistent with the call to examine theories, mostly developed and tested in Western settings, in a non-Western context. Our deliberate exploratory examination of cultural context is consistent with Johns' (2006) directions for future researchers in the field of organizational behavior. While this study provides some evidence for external validity or generalizability of the examined relationships, it also points to the need for more direct examinations of context by incorporating discrete contextual features (e.g., cultural values) in future examinations of POP.

\section{Implications for Practice}

Our study provides some valuable managerial implications. For example, managers should be wary of the harmful implications of workplace politics. They should address potential contributors to perceived organizational politics, such as ambiguous policies and procedures, poor communication, and lack of proper feedback and guidance to minimize the adverse effects on employees. Managers of organizations that are going through mergers, downsizing, or restructuring should be even more vigilant, as these processes also tend to increase uncertainty and politics in the work environment. It would be prudent for organizations to re-examine their selection criteria in hiring individuals, to include characteristics such as hope and efficacy, as 
these can buffer new hires from the influence of politics. The design and implementation of training interventions can benefit by incorporating methods that help in enhancing the psychological resources, especially hope and efficacy of employees so that they are better equipped to cope with demanding and stressful work environment.

\section{Strengths and Limitations}

The current study has several strengths. First, responding to the call of Fineman (2006), this study integrates the positivity- and negativity-oriented research. In particular, we enhance our understanding of the organizational politics and psychological capital theories in a new cultural setting significantly different from North America and Europe. Exploring the main and moderating effects in such setting extends our understanding and provides evidence for external validity of research domains dominated by Western samples. Second, we collected our filed data from multiple sources, which reduced the possibility of method bias. Detection of significant interactions for self-reported perceived politics and supervisory-reported performance, where the interaction accounted for $9 \%$ additional variance, is rare. Third, this study provides strong evidence for main effects of overall psychological capital on job satisfaction, and supervisorrated job performance. Finally, our findings provide support for the role of psychological capital

(i.e., hope and self-efficacy combined) as a threat-neutralizer as compared to previous findings of efficacy as a threat-amplifier.

This study has several limitations that need to be noted. One of the limitations has to do with common method bias. Although we attempted to circumvent this possibility by assessing job performance using supervisory ratings, this was not the case with the other examined variables. However, the obtained results for the main effects of POP are generally consistent when compared to those reported in past research. Moreover, significant interactions suggest that 
method variance was not an issue as it works against detection of such interaction effects. A second limitation is the slightly lower reliability of job satisfaction $(\alpha=.67)$. Nevertheless, the obtained associations between POP and outcomes are consistent with the meta analytic findings of Miller and colleagues (2008). A third limitation is that we included only two of the four dimensions of psychological capital. Although we do not expect our findings to change if the remaining two dimensions are included because efficacy and hope are the dominant dimensions and have stronger effects, some differences in effect size cannot be ruled out.

\section{Future Research Directions}

Future research in this area should examine the role of other plausible individual and contextual moderators in the relationship between perceived politics and outcomes. For example, exploring the effects of the Big Five traits on the POP-outcomes relationship might provide insight into our understanding of the interplay of person and situation factors in determining various attitudinal and behavioral outcomes. Acknowledging possible differences in the domain of POP across nations, future research needs a direct comparison of non-Western and Western samples to explore the moderating influence of discrete cultural contextual factors (e.g., cultural values). Future studies should also focus on providing a more detailed analysis of the dimensionality of POP and their relative influence on job outcomes.

Similarly, research may continue to explore the viability and vitality of PsyCap as a construct that can help improve our understanding of organizational behavior. Being a state-like characteristic that is amenable to development, psychological capital may hold better promise for organizational effectiveness against the dominant trait theories. PsyCap, being a composite of positive psychological resources, has inherent proactive coping mechanism and goal-orientation that may buffer against challenge and hindrance related stressors such as role stressors, heavy 
workload, time pressure, and job scope. Testing models that directly examine such role of PsyCap would provide more insight into the buffering capacities of these resources.

\section{Conclusion}

Asia has an important role in the global economy as multinationals are increasingly moving to Asian regions. Unless we test the theories largely developed in the US in non-Western settings, researchers and practitioners would have little confidence about their generalizability in those regions (Tsui et al., 2007). Our study provides some insights into the generalizability of concepts such as perceived organizational politics and psychological capital in Pakistan. More efforts, however, are required to extend and test complex models in different cultural settings. 


\section{References}

Agho, A. O., Price, J. L., \& Mueller, C. W. 1992. Discriminant validity of measures of job satisfaction, positive affectivity, and negative affectivity. Journal of Occupational Psychology, 65, 185-196.

Aiken, L., \& West, S. 1991. Multiple regression: Testing and interpreting interactions. Newbury Park, CA: Sage.

Allen, D. G., \& Griffeth, R. W. 1999. Job performance and turnover: A review and integrative multi-route model. Human Resource Management Review, 9, 525-548.

Avey, J. B., Luthans, F., \& Youssef, C. M. 2010. The additive value of psychological capital in predicting workplace attitudes and behaviors. Journal of Management, 36, 430-452.

Bandura, A. 1997. Self-efficacy: The exercise of control. New York: Freeman.

Bandura, A. 2012. On the functional properties of perceived self-efficacy revisited. Journal of Management, 38, 9-44.

Bandura, A., \& Locke, E. A. 2003. Negative self-efficacy and goal effects revisited. Journal of Applied Psychology, 88, 87-99.

Bobko, P. 1986. A solution to some dilemmas when testing hypotheses about ordinal interactions. Journal of Applied Psychology, 71, 323-326.

Bozeman, D. P., Perrewe, P. L., Hochwarter, W. A., \& Brymer, R. A. 2001. Organizational politics, perceived control, and work outcomes: Boundary conditions on the effects of politics. Journal of Applied Social Psychology, 31, 486-503.

Bryk, A.S., \& Raudenbush, S.W. 1992. Hierarchical Linear Models: Applications and Data Analysis Methods. Newbury Park, CA: Sage.

Caprara, G. V., Barbaranelli, C., Pastorelli, C., \& Cervone, D. 2004. The contribution of self- 
efficacy beliefs to psychosocial outcomes in adolescence: Predicting beyond global dispositional tendencies. Personality and Individual Differences, 37, 751-763.

Cavanaugh, M. A., Boswell, W. R., Roehling, M. V., \& Boudreau, J. W. 2000. An empirical examination of self-reported stress among managers. Journal of Applied Psychology, 85, $65-74$.

Chang, Chu-Hsiang., Rosen, C. C., \& Levy, P. E. 2009. The relationship between perceptions of organizational politics and employee attitudes, strain, and behavior: A meta-analytic examination. Academy of Management Journal, 52, 779-801.

Chaplin, W. F. 1991. The next generation of moderator research in personality psychology. Journal of Personality, 59, 143-178.

Chatterjee, S., \& Price, B. 1991. Regression diagnostics. New York: John Wiley.

Cohen, J., Cohen, P., West, S., \& Aiken, L. 2003. Applied multiple regression/correlation analysis for the behavioral sciences. Mahwah, NJ: Erlbaum.

Crawford, E. R., Lepine, J. A., \& Rich, B. L. 2010. Linking job demands and resources to employee engagement and burnout: A theoretical extension and meta-analytic test. Journal of Applied Psychology, 93, 834-848.

Ferris, G. R., \& Kacmar, K. M. 1992. Perceptions of organizational politics. Journal of Management, 18, 93-116.

Ferris, G. R., Perrewe, P. L., Anthony, W. P., \& Gilmore, D. C. 2000. Political skill at work. Organizational Dynamics, 28, 25-37.

Ferris, G. R., Russ, G. S., \& Fandt, P. M. 1989. Politics in organizations. In R. A. Giacalone \& Rosenfeld (Eds.), Impression management in the organization (pp. 143-170). Hillsdale, NJ: Lawrence Erlbaum. 
Fineman, S. 2006. On being positive: Concerns and counterpoints. Academy of Management Review, 31, 270-291.

Fredrickson, B. L. 2001. The role of positive emotions in positive psychology: The broaden-andbuild theory of positive emotions. American Psychologist, 56, 218-226.

Hair, J., Jr., Anderson, R., Tatham, R., \& Black, W. 1998. Multivariate data analysis, Fifth ed. Englewood Cliffs, NJ: Prentice-Hall.

Hobfoll, S. E. 2002. Social and psychological resources and adaptation. Review of General Psychology, 6, 307-324.

Hobfoll, S. E. 2011. Conservation of resource caravans and engaged settings. Journal of Occupational and Organizational Psychology, 84, 116-122.

Hofstede, G. H. 1983. National culture in four dimensions. International Studies of Management and Organization, 13, 46-74.

Hofstede, G. H. 1991. Cultures and organizations, software of the mind: Intercultural cooperation and its importance for survival. New York: McGraw-Hill.

Hofstede, G. H. 2001. Culture's Consequences: Comparing Values, Behaviors, Institutions, and Organizations across Nations. Thousand Oaks, CA: Sage. 2nd ed.

Jackofsky, E. F. 1984. Turnover and Job Performance: An Integrated Process Model. Academy of Management Review, 9, 74-83.

Johns, G. 2006. The essential impact of context on organizational behavior. Academy of Management Review, 31, 386-408.

Judge, T. A., Jackson, C. L., Shaw, C. V., Scott, B. A., \& Rich, B. L. 2007. Self-efficacy and work-related performance: the integral role of individual differences. Journal of Applied Psychology, 92, 107-127. 
Kacmar, K. M., Collins, B. J., Harris, K. J., \& Judge, T. A. 2009. Core self-evaluations and job performance: The role of the perceived work environment. Journal of Applied Psychology, 94, 1572-1580.

Kacmar, K. M., \& Ferris, G. R. 1991. Perceptions of organizational politics scale (POPS): Development and construct validation. Educational and Psychological Measurement, 51, 193-205.

Kapoutsis, I., Papalexandris, A., Nikolopoulos, A., Hochwarter, W. A., \& Ferris, G. R. 2011 Politics perceptions as moderator of the political skill-job performance relationship: A two-study, cross-national, constructive replication. Journal of Vocational Behavior, 78, $123-135$.

LePine, J. A., Podsakoff, N. P., \& LePine, M. A. 2005. A meta-analytic test of the challengestressor hindrance-stressor framework: An explanation for inconsistent relationships among stressors and performance. Academy of Management Journal, 48, 764-775.

Luthans, F. 2002. The need for and meaning of positive organizational behavior. Journal of Organizational Behavior, 23, 695-706.

Luthans, F., Avolio, B. J., Avey, J. B., \& Norman, S. M. 2007. Positive psychological capital: Measurement and relationship with performance and satisfaction. Personnel Psychology, $60,541-572$.

Luthans, F., \& Youssef, C. M. 2007. Emerging positive organizational behavior. Journal of Management, 33, 321-349.

Luthans, F., Youssef, C. M., \& Avolio, B. J. 2007. Psychological capital. New York: Oxford University Press.

Magaletta, P. R., \& Oliver, J. M. 1999. The hope construct, will and ways: Their relations with 
self-efficacy, optimism, and well-being. Journal of Clinical Psychology, 55, 539-551.

Miller, B. K., Rutherford, M. A., \& Kolodinsky, R. W. 2008. Perceptions of organizational politics: A meta-analysis of outcomes. Journal of Business and Psychology, 22, 209-222.

Nauta, A., van Vianen, A., van der Heijden, B., van Dam, K., \& Willemsen, M. 2009.

Understanding the factors that promote employability orientation: The impact of employability culture, career satisfaction, and role breadth self-efficacy. Journal of Occupational and Organizational Psychology, 82, 233-251.

Perrewe, P. L., Ferris, G. R., Frink, D. D., \& Anthony, W. P. 2000. Political skill: An antidote for workplace stressors. Academy of Management Executive, 14, 115-123.

Randall, M. L., Cropanzano, R., Bormann, C. A., \& Birjulin, A. 1999. Organizational politics and organizational support as predictors of work attitudes, job performance, and organizational citizenship behavior. Journal of Organizational Behavior, 20, 159-174.

Rosen, C. C., Levy, P. E., \& Hall, R. J. 2006. Placing perceptions of politics in the context of the feedback environment, employee attitudes, and job performance. Journal of Applied Psychology, 91, 211-220.

Seligman, M. E. P., \& Csikszentmihalyi, M. 2000. Positive psychology: An introduction. American Psychologist, 55, 5-14.

Snyder, C. R. 1994. Hope and optimism. Encyclopedia of human behavior, Vol. 2, 535-542. San Diego, CA: Academic Press.

Snyder, C. R., Irving, L., \& Anderson, J. 1991. Hope and health: Measuring the will and the ways. In C. R. Snyder\& D. R. Forsyth (Eds.), Handbook of social and clinical psychology (pp. 285-305). Elmsford, NY: Pergamon.

Stajkovic, A. D., \& Luthans, F. 1998a. Self-efficacy and work-related performance: A meta- 
analysis. Psychological Bulletin, 44, 580-590.

Stajkovic, A. D., \& Luthans, F. 1998b. Social cognitive theory and self-efficacy: Going beyond traditional motivational and behavioral approaches. Organizational Dynamics, 26, 62-74.

Tabachnick, B., \& Fidell, L. 2001. Using multivariate statistics, 4th ed. Needham Heights, MA: Allyn \& Bacon.

Treadway, D. C., Ferris, G. R., Hochwarter, W. A., Perrewe, P. L., Witt, L. A., \& Goodman, J. M. 2005. The role of age in perceptions of politics-job performance relationship: A three-study constructive replication. Journal of Applied Psychology, 90, 872- 881.

Tsui, A. S., Nifadkar, S. S., \& Ou, Y. A. 2007. Cross-national, cross-cultural organizational behavior research: Advances, gaps, and recommendations. Journal of Management, 33, $426-478$.

Vigoda, E. 2000. Organizational politics, job attitudes, and work outcomes: Exploration and implications for the public sector. Journal of Vocational Behavior, 57, 326-347.

Vigoda, E. 2001. Reactions to organizational politics: A cross-cultural examination in Israel and Britain. Human Relations, 54, 1483-1518.

Williams, L. J., \& Anderson, S. E. 1991. Job satisfaction and organizational commitment as predictors of organizational citizenship and in-role behaviors. Journal of Management, $17,601-617$.

Youssef, C. M., \& Luthans, F. 2007. Positive organizational behavior in the workplace: The impact of hope, optimism, and resiliency. Journal of Management, 33, 774-800. 
Table 1

Means, Standard Deviations, Correlations, and Reliabilities

\begin{tabular}{|c|c|c|c|c|c|c|c|c|c|c|}
\hline & Mean & S.D & 1 & 2 & 3 & 4 & 5 & 6 & 7 & 8 \\
\hline 1. Age & 30.82 & 8.10 & -- & & & & & & & \\
\hline 2. Tenure & 4.89 & 6.49 & $.76^{* *}$ & -- & & & & & & \\
\hline 3. Organization ${ }^{\mathrm{a}}$ & 0.17 & 0.37 & $.36^{* *}$ & $.43 * *$ & -- & & & & & \\
\hline 4. PsyCap & 4.52 & 0.82 & .01 & .08 & .12 & $(.89)$ & & & & \\
\hline 5. POP & 3.06 & 0.54 & -.03 & -.01 & -.05 & .11 & $(.73)$ & & & \\
\hline 6. Turnover Intentions & 2.92 & 0.93 & $-.30 * *$ & $-.29 * *$ & $-.35^{* *}$ & -.05 & $.30 * *$ & $(.76)$ & & \\
\hline 7. Job Satisfaction & 3.62 & 0.52 & $.14^{*}$ & $.15^{*}$ & $.24 * *$ & $.49 * *$ & $-.21 * *$ & $-.29 * *$ & $(.67)$ & \\
\hline 8. Job Performance & 3.80 & 0.59 & -.01 & .03 & .05 & $.43 * *$ & -.08 & -.09 & $.53 * *$ & $(.77)$ \\
\hline
\end{tabular}

Note. $N=231$; Alpha reliabilities presented in parenthesis. POP = Perceived Organizational Politics; PsyCap = Psychological Capital.

a. Organizational type: $0=$ Private; $1=$ Public.

$* p<.05$

$* * p<.01$ 
Table 2

Results for Main Effects and Moderated Regression Analyses

\begin{tabular}{|c|c|c|c|c|c|c|}
\hline & \multicolumn{2}{|c|}{ Turnover Intentions } & \multicolumn{2}{|c|}{ Job Satisfaction } & \multicolumn{2}{|c|}{ Job Performance } \\
\hline & $\beta$ & $\Delta R^{2}$ & $\beta$ & $\Delta R^{2}$ & $\beta$ & $\Delta R^{2}$ \\
\hline \multicolumn{7}{|l|}{ Step 1} \\
\hline Age & $-.16^{*}$ & & .04 & & -.07 & \\
\hline Tenure & -.06 & & .03 & & .06 & \\
\hline Organization $^{\mathrm{a}}$ & $-.27 * * *$ & $.16 * * *$ & $.21 * *$ & $.06^{* *}$ & .06 & .00 \\
\hline \multicolumn{7}{|l|}{ Step2 } \\
\hline Age & $-.16^{*}$ & & .09 & & -.03 & \\
\hline Tenure & -.06 & & .01 & & .01 & \\
\hline Organization $^{a}$ & $-.25 * * *$ & & $.14 * *$ & & .00 & \\
\hline POP & $.29 * * *$ & & $-.24 * * *$ & & $-.11 *$ & \\
\hline PsyCap & -.05 & $.08 * * *$ & $.51 * * *$ & $.28 * * *$ & $.44 * * *$ & $.19 * * *$ \\
\hline \multicolumn{7}{|l|}{ Step 3} \\
\hline Age & $-.15^{*}$ & & .09 & & -.01 & \\
\hline Tenure & -.06 & & .01 & & .00 & \\
\hline Organization $^{a}$ & $-.26 * * *$ & & $.14 * *$ & & .00 & \\
\hline POP & $.26 * * *$ & & $-.29 * * *$ & & $-.21 *$ & \\
\hline PsyCap & -.01 & & $.56^{* * * *}$ & & $.54 * * *$ & \\
\hline POP x PsyCap & $.14 *$ & $.02 *$ & $.17 * *$ & $.02 * *$ & $.33 * * *$ & $.09 * * *$ \\
\hline
\end{tabular}

Note. $N=231 ;$ POP = Perceived Organizational Politics; PsyCap = Psychological Capital .

a. Organizational type: $0=$ Private $1=$ Public .

$* p<.05$

$* * p<.01$

$* * * p<.001$ 
Figure 1

Interactive Effects of PsyCap and POP on Turnover Intentions

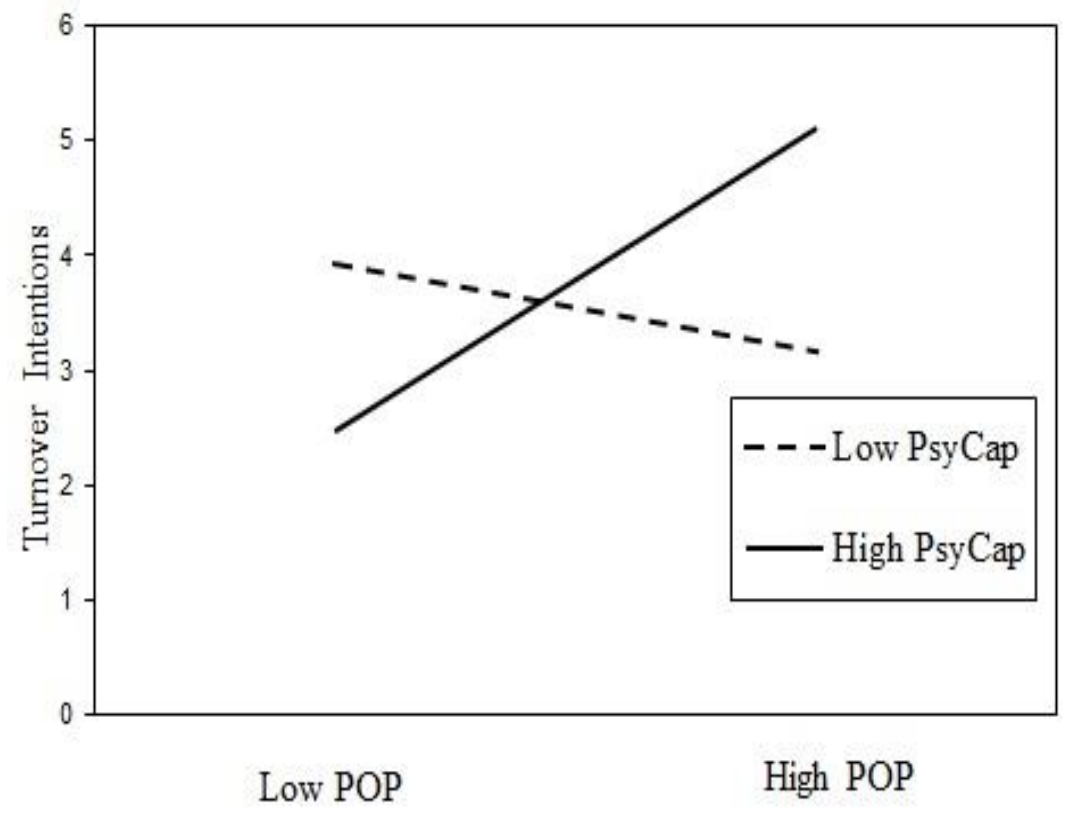


Figure 2

Interactive Effects of PsyCap and POP on Job Satisfaction

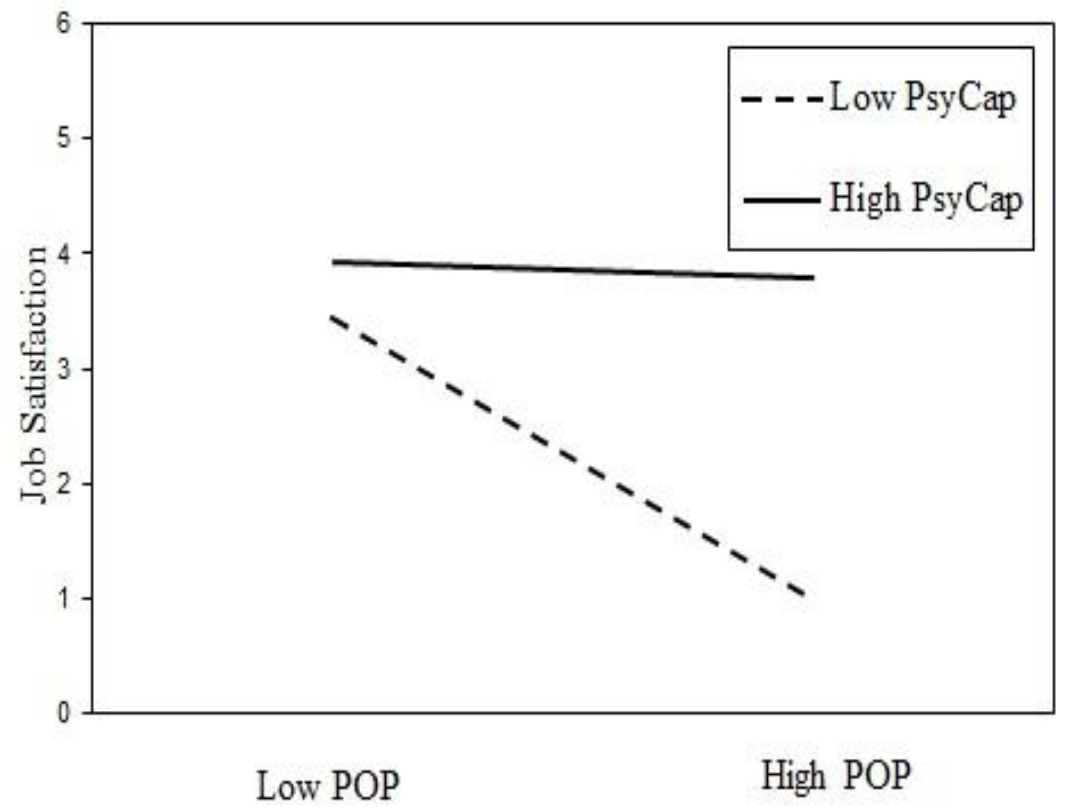




\section{Figure 3}

Interactive Effects of PsyCap and POP on Supervisory-Rated Job Performance

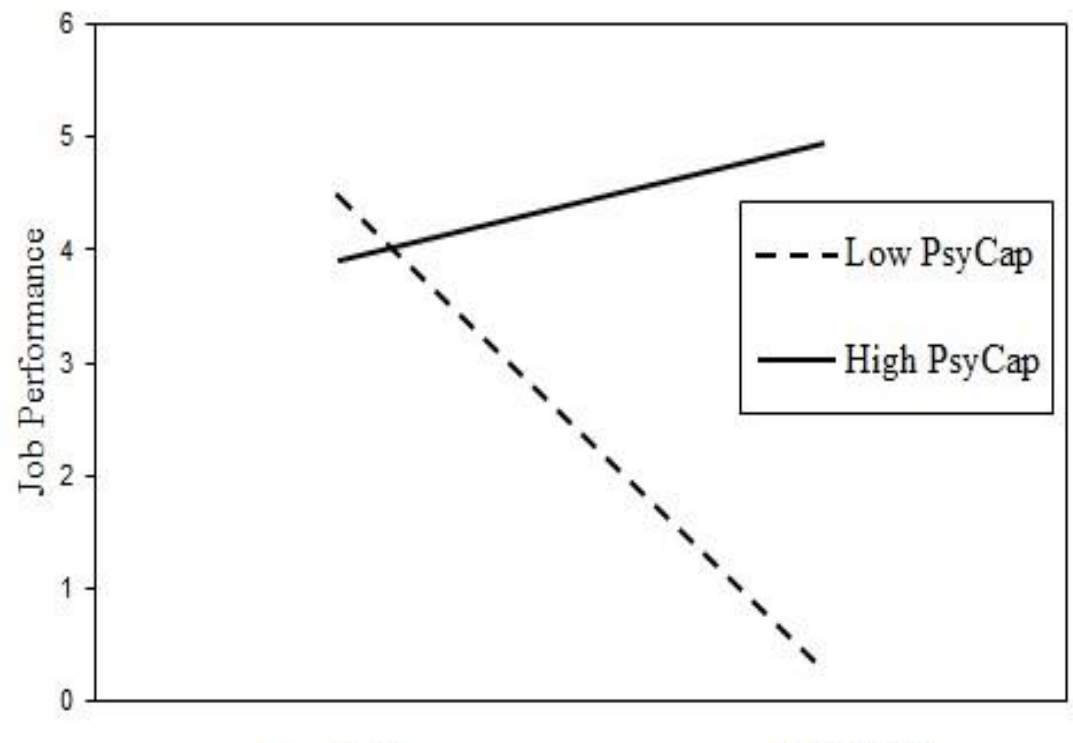

Low POP

High POP 